\title{
Isolation and Characterization of Kimchi Starters Leuconostoc mesenteroides PBio03 and Leuconostoc mesenteroides PBio104 for Manufacture of Commercial Kimchi
}

\author{
Kang Wook Lee*, Geun Su Kim, A Hyong Baek, Hyun Sun Hwang, Do Young Kwon, Sang Gu Kim, \\ and Sang Yun Lee
}

Pulmuone Institute of Technology, Cheongju 28164, Republic of Korea

\begin{abstract}
This study was focused on developing and obtaining a kimchi starter for use in commercial kimchi production. Kimchi varieties made with selected starters are of high quality, have high levels of mannitol, and extended shelf life. The starters were screened for properties such as mannitol production, low gas/acid production, and acid resistance. Finally, kimchi fermentation testing was performed using selected LAB starters. Kimchi samples were prepared with lactic acid bacteria (LAB) starters, including Leuconostoc mesenteroides PBio03 and Leuconostoc mesenteroides PBio104. The LAB starters are isolated from kimchi and can grow under $\mathrm{pH} 3.0$ and low temperature conditions of $5^{\circ} \mathrm{C}$. Four kimchi samples were fermented and stored for 28 days at $5^{\circ} \mathrm{C}$. The kimchi samples made with starters (PBio03 and PBio 104) had better quality (production of mannitol and maintenance of heterofermentative LAB dominance) than the non-starter kimchi samples. In the starter kimchi, Leu. mesenteroides was the dominant $L A B$, comprising $80 \%$ and $70 \%$ of total LAB counts at 7 and 21 days, respectively. Mannitol content of the kimchi with Leu. mesenteroides PBio03 was 1,423 $\pm 19.1 \mathrm{mg} /$ $100 \mathrm{~g}$ at 28 days, which was higher than that of the non-starter kimchi sample $(1,027 \pm 12.2 \mathrm{mg} / 100$ g). These results show the possibility of producing kimchi with improved qualities using Leu. mesenteroides PBio03 and PBio104 as starters.
\end{abstract}

Keywords: Kimchi fermentation, lactic acid bacteria, kimchi starter, Leuconostoc mesenteroides, mannitol production

Received: January 9, 2020 Accepted: April 2, 2020

First published online: April 9, 2020

*Corresponding author Phone: +82-43-903-3894 Fax: +82-772-1909 E-mail:kwleeh@pulmuone.co.kr

pISSN 1017-7825 eISSN 1738-8872

Copyright(C) 2020 by The Korean Society for Microbiology and Biotechnology

\section{Introduction}

Kimchi is a traditional Korean food consisting of vegetables such as Chinese cabbage, radish, and various other ingredients including red pepper, garlic and ginger which are fermented by lactic acid bacteria (LAB) under low temperature conditions (approximately $0-10^{\circ} \mathrm{C}$ ) to ensure optimal ripening and preservation [1]. The production of organic acids from carbohydrates during kimchi fermentation and the resulting reductions in $\mathrm{pH}$ maintain the freshness of kimchi during storage $[2,3]$. Natural kimchi fermentation leads to the growth of various LAB, causing variations in the quality. The use of LAB starters has been considered as an alternative method for industrial production of standardized kimchi, and the purposes of starters to kimchi include sensory characteristic improvement, shelf life extension, and induction of functional properties.

Many studies on kimchi microbial communities have been performed using culture-dependent and independent approaches. These studies have shown that LAB, including Leuconostoc spp., Lactobacillus spp., and Weissella spp., play the most important roles in kimchi fermentation [4]. In natural kimchi fermentation, heterofermentative LAB such as Leuconostoc spp. and Weissella spp. predominate in the early and middle stages of fermentation [2]. As the kimchi changes and becomes more acidic, homofermentative LAB such as Lactobacillus spp. become predominant. This predominance can lead to kimchi being excessively acidic in taste and having a soft texture [5]. Yeasts in kimchi fermentation are responsible for softening the texture of kimchi as well as generating off-flavors during the over-ripening stage, thereby producing a product of unsuitable quality $[6,7]$. It takes almost 1 month to reach the over-ripening stage from the initiation of kimchi fermentation. Therefore, kimchi manufacturers have assigned a shelf life of 28 days to industrial kimchi even under refrigerated storage conditions [2].

The non-starter fermentation process primarily occurs by microorganisms naturally present in the raw materials. Such a natural and randomly occurring fermentation process depends on several conditions and cannot be controlled; thus, the product quality can unpredictably vary from batch to batch [8]. However, in starter 
fermentation, the changes in microorganisms indicate a different pattern.

Generally, mannitol is produced via catalytic hydrogenation of fructose and sucrose. Among LAB, only heterofermentative species are known to convert fructose into mannitol, and species belonging to the genera Leuconostoc, Oenococcus, and Lactobacillus have been reported to effectively produce mannitol [9-11].

Here, we screened and selected a kimchi starter, namely Leuconostoc spp., for mannitol production, low gas/acid production, and strong acid resistance. Kimchi samples were prepared using kimchi starter culture of Leuconostoc mesenteroides PBio03 and Leu. mesenteroides PBio104. The characteristic properties of kimchi samples were tested over a period of 28 days at $5^{\circ} \mathrm{C}$.

\section{Materials and Methods}

\section{Isolation, Screening and Identification of LAB (Kimchi Starter)}

Approximately 250 strains were isolated from kimchi samples purchased at local markets in Daegu and Jinju, Republic of Korea, in the spring of 2019. Each of the samples was diluted with sterilized $0.85 \%(\mathrm{w} / \mathrm{v}) \mathrm{NaCl}$ solution via ten-fold serial dilution. Next, $0.1 \mathrm{ml}$ from each of the diluted samples was serially diluted with $9 \mathrm{ml}$ saline ( $3 \mathrm{M}$ Diluent). These subsequently diluted samples were plated onto De Man Rogosa Sharpe (MRS; Becton, Dickinson and Company, USA) agar to screen for LAB strains. The plates were incubated at $30^{\circ} \mathrm{C}$ for $24 \mathrm{~h}$. After incubation, the colonies were examined and a single colony was selected.

The isolated strains were inoculated into $10 \mathrm{ml}$ of in vitro MRS broth contained in a Durham tube measuring $30 \mathrm{~mm}$ in height and subsequently cultured at $25^{\circ} \mathrm{C}$ for $24 \mathrm{~h}$. The height of gas collected in the Durham tube was measured to determine the degree of gas generation, and strains that generated gas up to $\leq 5 \mathrm{~mm}$ were selected. The isolated strain colonies were each inoculated into $10 \mathrm{ml}$ of MRS broth. For measuring acid production, $\mathrm{pH}$ was measured using a $\mathrm{pH}$ meter after incubation at $25^{\circ} \mathrm{C}$ for $24 \mathrm{~h}$, and strains having a $\mathrm{pH}$ of $\geq 4.4$ were selected. The tests for acid tolerance of strains to $\mathrm{pH} 2,3$ and 4 were performed following the methods by Lee et al. [12]. The last screened properties of kimchi starter were production of mannitol. The growth of starter strains was measured in MRS broth at different conditions such as temperature $\left(5^{\circ} \mathrm{C}, 10^{\circ} \mathrm{C}, 15^{\circ} \mathrm{C}, 20^{\circ} \mathrm{C}, 30^{\circ} \mathrm{C}\right.$, and $\left.40^{\circ} \mathrm{C}\right), \mathrm{pH}(\mathrm{pH} 2.0, \mathrm{pH}$ 3.0 , and $\mathrm{pH} 4.0$ ) and $\mathrm{NaCl}$ concentrations (3\%, 5\%, and 7\%).

Screened strains were identified by $16 \mathrm{~S}$ rRNA gene sequencing which was amplified by PCR. PCR was performed using the primers 27F (5'-AGAGTTTGATCMTGGCTCAG- $3^{\prime}$ ) and 1492R (5'-TACGGYTACCTT GTTACGACTT-3'). PCR conditions were 35 cycles at $95^{\circ} \mathrm{C}$ for $1 \mathrm{~min}, 55^{\circ} \mathrm{C}$ for $1 \mathrm{~min}$, and $72^{\circ} \mathrm{C}$ for $2 \mathrm{~min}$. PCRamplified products (approximately 1400 base pairs) were confirmed by performing agarose gel electrophoresis, and nucleotide sequences were determined at Macrogen Co. (https://dna.macrogen.com/kor/index.jsp). The BLAST program was used to identify homologous $16 \mathrm{~S}$ rRNA gene sequences in the database (http://www.ncbi. nlm.nih.gov/BLAST).

\section{Preparation of Kimchi Samples}

Kimchi was prepared using Chinese cabbage as the main raw material. Chinese cabbage was soaked in 9-13\% $(\mathrm{w} / \mathrm{v})$ salt solution for $24 \mathrm{~h}$. The soaked Chinese cabbage was washed with tap water three times, and the excess water was drained off for $3 \mathrm{~h}$. Kimchi seasoning was prepared by mixing shredded radish, red pepper, garlic, ginger, onion, green onion, jeotgal, and sucrose at a ratio of 55: 9.5: 7.5: 1: 7.5: 7.5: 9.5:2.5. The seasoning was added to the salted Chinese cabbage at a ratio $(\mathrm{w} / \mathrm{w})$ of 70:30 (Chinese cabbage: kimchi seasoning). The starter strains were grown in MRS broth overnight at $30^{\circ} \mathrm{C}$, and cells were recovered via centrifugation. The cells were washed two times with sterile water and resuspended in $2 \mathrm{ml}$ sterile water. The cells were added to the Chinese cabbage together with the seasoning. In this study, Leu. mesenteroides PBio03 and PBio104 were the starters used for kimchi samples $C$ and $D$, respectively. The starter culture used for kimchi sample $B$ is the same as that used in kimchi fermentation at present, i.e., the culture was a mixture of three kinds of LAB (Leu. mesenteroides, Leu. citreum, and Lactobacillus plantarum). The prepared kimchi samples were placed in plastic containers, each weighing $1 \mathrm{~kg}$, and stored at $5^{\circ} \mathrm{C}$ for 28 days. The kimchi samples were examined weekly.

\section{pH, Total Acidity, and Mannitol Analysis of Kimchi Samples}

Kimchi samples were macerated using a blender (Shinil electric mixer SMX-JC15MR, Korea). Then, the macerated samples were centrifuged (Microcentrifuge 1730R, LABOGENE, Korea) for $20 \mathrm{~min}$ at 12,000 g, and the supernatants were tested for $\mathrm{pH}$ and total acidity (TA). The $\mathrm{pH}$ was measured using a $\mathrm{pH}$ meter (Orion STAR A211 pH meter, Thermo Scientific, USA), while the filtrates were titrated with $0.1 \mathrm{~N} \mathrm{NaOH}$ to a $\mathrm{pH}$ of 8.3 for TA analysis. The supernatant samples of kimchi were analyzed for the presence of mannitol using high-performance liquid chromatography (HPLC, 1100 series, Agilent Co., USA) employing an Asahipak NH2P-50 4E (Column size 4.6 mm I.D. $\times 250 \mathrm{~mm}$, Shodex, Japan), and an RI detector (1260 series, Agilent Co.). An acetonitrile and water mixture $(75: 25, \mathrm{v} / \mathrm{v})$ was used as the mobile phase at $1.5 \mathrm{ml} / \mathrm{min}$.

\section{Microbial Analysis of Kimchi Samples}

Kimchi samples were mixed with $0.85 \% \mathrm{NaCl}$ solution and homogenized for 2 min using a stomacher (BagMixer 400, Interscience, France). The homogenates were serially diluted with $9 \mathrm{ml}$ saline (3M Diluent, USA), and the diluted samples were spread onto a plate count agar (PCA, USA) for obtaining total viable bacteria counts as well as on Petrifilm_EC (3M Health Care, USA) for obtaining the coliform bacteria count, MRS (PCA) agar for LAB count, and Dichloran Rose Bengal Chloramphenicol (DRBC, USA) agar for yeast.

The MRS agar plates were counted after $48 \mathrm{~h}$ of incubation at $30^{\circ} \mathrm{C}$. Thirty colonies were selected from each MRS agar plate and prepared for DNA sequencing. LAB strains were identified by $16 \mathrm{~S}$ rRNA gene sequencing 
Table 1. Screening of kimchi starter by gas/acid production.

\begin{tabular}{|c|c|c|c|c|c|c|c|}
\hline $\begin{array}{c}\text { Strain } \\
\text { No. }\end{array}$ & Identified strain & $\begin{array}{c}\text { Gas } \\
\text { production } \\
(\mathrm{cm})\end{array}$ & $\begin{array}{l}\text { Acid } \\
\text { production } \\
(\mathrm{pH})\end{array}$ & $\begin{array}{c}\text { Strain } \\
\text { No. }\end{array}$ & Identified strain & $\begin{array}{c}\text { Gas } \\
\text { production } \\
(\mathrm{cm})\end{array}$ & $\begin{array}{c}\text { Acid } \\
\text { production } \\
(\mathrm{pH})\end{array}$ \\
\hline 1 & Weissella koreensis & $++(0.7)^{*}$ & 4.69 & 63 & Weissella koreensis & $++(0.6)$ & 4.60 \\
\hline 3 & Leuconostoc mesenteroides & $++(0.7)$ & 4.50 & 67 & Weissella koreensis & $++(0.8)$ & 4.68 \\
\hline 7 & Weissella koreensis & $+(0.2)$ & 4.70 & 69 & Weissella koreensis & $++(0.5)$ & 4.77 \\
\hline 9 & Weissella koreensis & $+(0.4)$ & 4.74 & 71 & Weissella koreensis & $++(0.8)$ & 4.70 \\
\hline 10 & Weissella koreensis & $+(0.3)$ & 4.72 & 72 & Weissella koreensis & $++(0.8)$ & 4.75 \\
\hline 15 & Weissella koreensis & $+(0.2)$ & 4.75 & 88 & Weissella koreensis & $++(0.8)$ & 4.68 \\
\hline 27 & Weissella koreensis & $++(0.6)$ & 4.71 & 93 & Weissella koreensis & $++(0.7)$ & 4.77 \\
\hline 31 & Weissella koreensis & $++(0.6)$ & 4.75 & 103 & Weissella koreensis & $++(0.8)$ & 4.80 \\
\hline 32 & Weissella soli & $+(0.4)$ & 4.81 & 104 & $\begin{array}{l}\text { Leuconostoc } \\
\text { mesenteroides }\end{array}$ & $++(0.6)$ & 4.48 \\
\hline 37 & Weissella koreensis & $++(0.7)$ & 4.74 & 112 & Weissella koreensis & $++(0.7)$ & 4.50 \\
\hline 38 & Weissella koreensis & $++(0.7)$ & 4.71 & 122 & $\begin{array}{l}\text { Lactobacillus sakei } \\
\text { subsp. sakei }\end{array}$ & $++(0.7)$ & 5.53 \\
\hline 52 & Weissella koreensis & $++(0.6)$ & 4.77 & 185 & Lactobacillus sakei & $++(0.8)$ & 4.78 \\
\hline
\end{tabular}

${ }^{*}+, 0.1 \mathrm{~mm}-0.5 \mathrm{~mm} ;++, 0.6 \mathrm{~mm}-1.0 \mathrm{~mm} ;++, 1.1 \mathrm{~mm}-1.5 \mathrm{~mm}$

which was amplified by PCR. PCR method was mentioned previously (Isolation, Screening and Identification of $\mathrm{LAB})$.

\section{Sensory Evaluation of Kimchi Samples}

Sensory evalutions of kimchi samples were done at 7 days of storage time. The test group consisted of 5 people (men:women $=2: 3$ ) and the average age was 35.3 years. A 5-point scale for taste, color, flavor, texture and overall acceptability was used.

\section{Results and Discussion}

Isolation and Screening of LAB Starters

About $250 \mathrm{LAB}$ strains were isolated from various kimchi samples. Screening revealed twenty-five of them to be low gas-producing and low acid-producing strains (Table 1). In addition, seven strains were found to be resistant to low $\mathrm{pH}$ conditions (Table 2), and when exposed to simulated in vitro gastric juice of $\mathrm{pH} 3$, the survival rates ranged from $64.8-78.8 \%$. Gas and acid production of kimchi starter are important properties in the kimchi industry, as they prevent kimchi packaging expansion and extend intake period, respectively. The acid resistance affects the dominance rate of kimchi starter during fermentation. Finally, screening was carried out to select a starter strain for high production of mannitol. The results of the mannitol production of tested strains in MRS are presented in Table 3. In MRS medium (3\% fructose), mannitol concentrations of 25.0 and $19.2 \mathrm{~g} / \mathrm{l}$, were achieved by Leu. mesenteroides PBio03 and Leu. mesenteroides PBio104, respectively. Among LAB, only heterofermentative species such as Leuconostoc are known to convert fructose into mannitol [2, 8, 15]. In other reports, the results of mannitol production in MRS broth for Leu. citreum KACC 91348P, Leu. mesenteroides D1 and Leu. mesenteroides B-742C were measured at 30.4, 27.3, and 29.4 g/l (MRS broth containing $4 \%$ fructose) [11]. The strains were tested

Table 2. Acid resistance of isolated strains.

\begin{tabular}{cllcc}
\hline \multirow{2}{*}{ No. Strains } & \multicolumn{3}{c}{ Acid resistance (survival rates, \%) } \\
\cline { 3 - 5 } & & $\mathrm{pH} 2.0,2 \mathrm{~h}$ & $\mathrm{pH} 3.0,2 \mathrm{~h}$ & $\mathrm{pH} 4.0,2 \mathrm{~h}$ \\
\hline 3 & Leuconostoc mesenteroides & $20.6( \pm 0.1)$ & $72.4( \pm 0.2)$ & $90.0( \pm 0.4)$ \\
7 & Weissella koreensis & $21.3( \pm 0.2)$ & $70.4( \pm 0.3)$ & $86.5( \pm 0.2)$ \\
9 & Weissella koreensis & $23.5( \pm 0.4)$ & $68.2( \pm 0.3)$ & $84.0( \pm 0.2)$ \\
15 & Weissella koreensis & $23.2( \pm 0.3)$ & $68.4( \pm 0.7)$ & $84.2( \pm 0.5)$ \\
69 & Weissella koreensis & $14.8( \pm 0.6)$ & $64.8( \pm 0.1)$ & $74.4( \pm 0.3)$ \\
104 & Leuconostoc mesenteroides & $21.4 .( \pm 0.6)$ & $66.4( \pm 0.2)$ & $88.4( \pm 0.3)$ \\
122 & Lactobacillus sakei subsp. sakei & $54.2( \pm 0.2)$ & $78.8( \pm 0.2)$ & $98.4( \pm 0.4)$ \\
\hline
\end{tabular}

Table 3. Mannitol production of isolated strains.

\begin{tabular}{clc}
\hline No. & \multicolumn{1}{c}{ Strain } & Mannitol production $(\mathrm{g} / 100 \mathrm{~g})$ \\
\hline 3 & Leuconostoc mesenteroides PBio03 & 2.5 \\
7 & Weissella koreensis PBio07 & 0.48 \\
9 & Weissella koreensis PBio09 & 0.43 \\
104 & Leuconostoc mesenteroides PBio104 & 1.92 \\
Con & Leu. mesenteroides WK32 + Leu. citreum KM20 & 1.62 \\
\hline
\end{tabular}


Table 4. Growth characteristics of isolated strains.

\begin{tabular}{|c|c|c|c|c|c|c|c|c|c|c|c|c|}
\hline \multirow{2}{*}{ Isolated strains } & \multicolumn{6}{|c|}{ Temperature } & \multicolumn{3}{|c|}{$\mathrm{pH}$} & \multicolumn{3}{|c|}{$\mathrm{NaCl}$ concentration } \\
\hline & $5^{\circ} \mathrm{C}$ & $10^{\circ} \mathrm{C}$ & $15^{\circ} \mathrm{C}$ & $20^{\circ} \mathrm{C}$ & $30^{\circ} \mathrm{C}$ & $40^{\circ} \mathrm{C}$ & 2.0 & 3.0 & 4.0 & $3 \%$ & $5 \%$ & $7 \%$ \\
\hline Leu. mesenteroides PBio03 & + & + & + & + & + & + & - & + & + & + & + & + \\
\hline Leu. mesenteroides $\mathrm{PBi} 104$ & + & + & + & + & + & + & - & + & + & + & + & + \\
\hline Weissella koreensis $\mathrm{PBio07}$ & - & + & + & + & + & + & - & + & + & + & + & + \\
\hline Weissella koreensis PBio09 & + & + & + & + & + & - & - & + & + & + & + & + \\
\hline
\end{tabular}

+, Growth; -, No growth

for growth in MRS broth in different conditions such as temperature, $\mathrm{pH}$ and $\mathrm{NaCl}$ concentrations. The selected strains (PBio03, PBio104) were able to grow at $5^{\circ} \mathrm{C}, \mathrm{pH} 3.0$ and $7 \% \mathrm{NaCl}$ concentration (Table 4).

pH and TA of Kimchi Samples

The initial $\mathrm{pH}$ values of kimchi samples immediately after preparation were 5.51-5.61 (Fig. 1A), and all kimchi samples showed a reduction in $\mathrm{pH}$ during fermentation and storage (28 days). During fermentation, Leu. mesenteroides, a heterolactic fermentation-type LAB, and other LAB produced lactic acid and acetic acid, resulting in $\mathrm{pH}$ reductions in the kimchi samples. The $\mathrm{pH}$ of kimchi A (a non-starter sample) was $5.23 \pm 0.02$ at 7 days, which was the highest among kimchi samples. Other kimchi samples (LAB-added samples) showed lower $\mathrm{pH}$ values than kimchi $\mathrm{A}$ : kimchi $\mathrm{B}, 4.67$; kimchi $\mathrm{C}$, 4.90; and kimchi $\mathrm{D}, 4.82$. The kimchi $\mathrm{C}$ and $\mathrm{D}$ samples to which the isolated LAB starter strains had been added showed higher $\mathrm{pH}$ values than those shown by the previously used kimchi samples containing LAB starters. The $\mathrm{pH}$ profile was similar to that of other reported typical kimchi fermentations $[4,13]$

The TA values of the kimchi samples changed with the $\mathrm{pH}$ values but in a reverse direction (Fig. 1B). Kimchi samples showed TA values of $0.27-0.33$. The TA values increased with fermentation time, and a significant increase occurred between 7 and 14 days, similar to the changes in $\mathrm{pH}$ values. This result can be attributed to the increased total LAB count between 7 and 14 days. Kimchi B showed the highest TA value of $0.82 \pm 0.03$ at 28 days, whereas the other kimchi samples showed TA values of $0.71-0.75$. Kimchi $C$ showed the lowest TA value $(0.71 \pm$ 0.02). Kimchi is in its best state for consumption when its TA value reaches 0.6-0.8 during fermentation [14]. Therefore, kimchi samples were well fermented and ready for consumption after 7 days, and their edibility was maintained for approximately 21 days.

\section{Analysis of Mannitol and Sugar Content in Kimchi Samples}

Mannitol content in kimchi samples was analyzed after 28 days of storage time (Fig. 2). At 28 days, mannitol content in kimchi D (containing Leu. mesenteroides PBio104) was $1,212 \pm 9.6 \mathrm{mg} / 100 \mathrm{~g}$; kimchi C (containing Leu. mesenteroides PBio03), 1,423 $\pm 19.1 \mathrm{mg} / 100 \mathrm{~g}$, which was the highest; and non-starter kimchi (sample A), 1,027 \pm $12.2 \mathrm{mg} / 100 \mathrm{~g}$, which was the lowest. The mannitol content in kimchi $\mathrm{C}$ was $138.5 \%$ and $107.2 \%$ higher than that in non-starter kimchi (A) and kimchi B (mix LAB starter), respectively.

The mannitol content in kimchi B was $1,327 \pm 7.2 \mathrm{mg} / 100 \mathrm{~g}$ at 28 days. Major free sugars detected included glucose and fructose, which have been known to play several roles as carbon sources for LAB metabolism during kimchi fermentation. In addition, we analyzed mannitol of commercially available kimchi products (competitor products). As a result, the mannitol content in the products of other companies were $1,250 \mathrm{mg} / 100 \mathrm{~g}$ and $960 \mathrm{mg} /$ $100 \mathrm{~g}$ at 28 days, each. These results should serve as an advantage in our future plan, which is to conduct fieldtesting within three months and apply it to some of the products at our own company. At 0 days, the fructose and glucose contents in kimchi samples were $1,497-1,548 \mathrm{mg} / 100 \mathrm{~g}$ and 1,505-1,534 mg/100 g, respectively (Fig. 2).

A

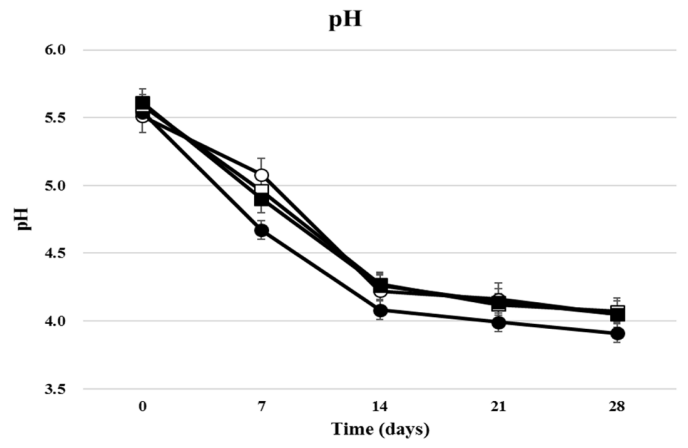

B

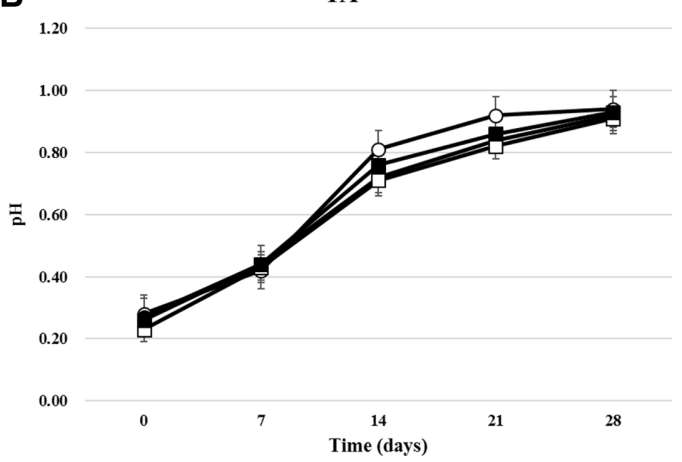

Fig. 1. Changes in pH, titratable acidity (TA) of kimchi samples during fermentation (four weeks). (A) pH, (B) TA: $\bigcirc$, Kimchi A (non-starter); $\bigcirc$, Kimchi B (LAB mix starter); $\square$, Kimchi C (Leu. mesenteroides PBio03); $\mathbf{\square}$, Kimchi D (Leu. mesenteroides PBio104). 


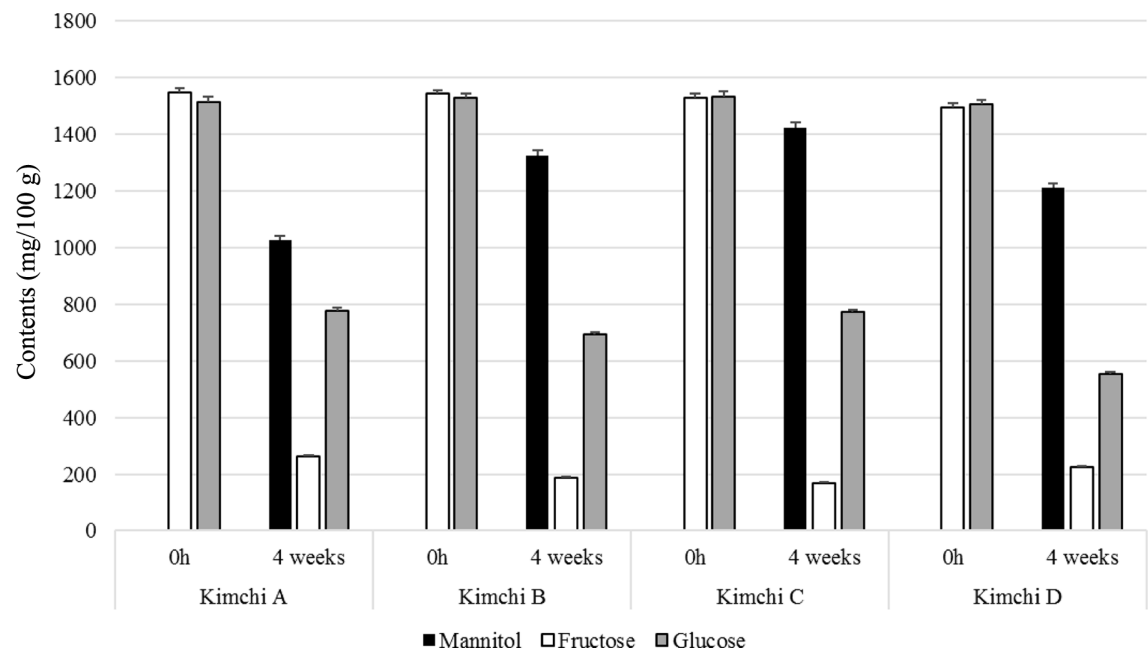

Fig. 2. Mannitol and sugar contents of kimchi fermentation by non-starter or starter strains at 4-week storage times. Kimchi A, non-starter kimchi; Kimchi B, LAB mix starter (Leu. mesenteroides, Leu. citreum and $L b$. plantarum); Kimchi C, Leu. mesenteroides PBio03 starter; Kimchi D, Leu. mesenteroides PBio104); Black box, mannitol; Grey box, fructose, White box, Glucose; Sucrose, Lactose, Maltose are not detected.

However, the fructose and glucose were used for the growth of lactic acid bacteria and mannitol production, and gradually decreased. At 28 days, the fructose and glucose contents in kimchi samples decreased to 170-264 mg/ $100 \mathrm{~g}$ and $555-778 \mathrm{mg} / 100 \mathrm{~g}$, respectively. Another study reported that mannitol production was inversely correlated with a decrease in fructose and glucose content [15].

\section{Microbial Analysis and Sensory Evaluation of Kimchi Samples}

Immediately after the preparation of kimchi samples, the number of LAB was $5.70 \times 10^{5} \mathrm{CFU} / \mathrm{g}$ for kimchi A (non-starter), and the number increased continuously to $5.90 \times 10^{8} \mathrm{CFU} / \mathrm{g}$ during 28 days of storage at $5^{\circ} \mathrm{C}$
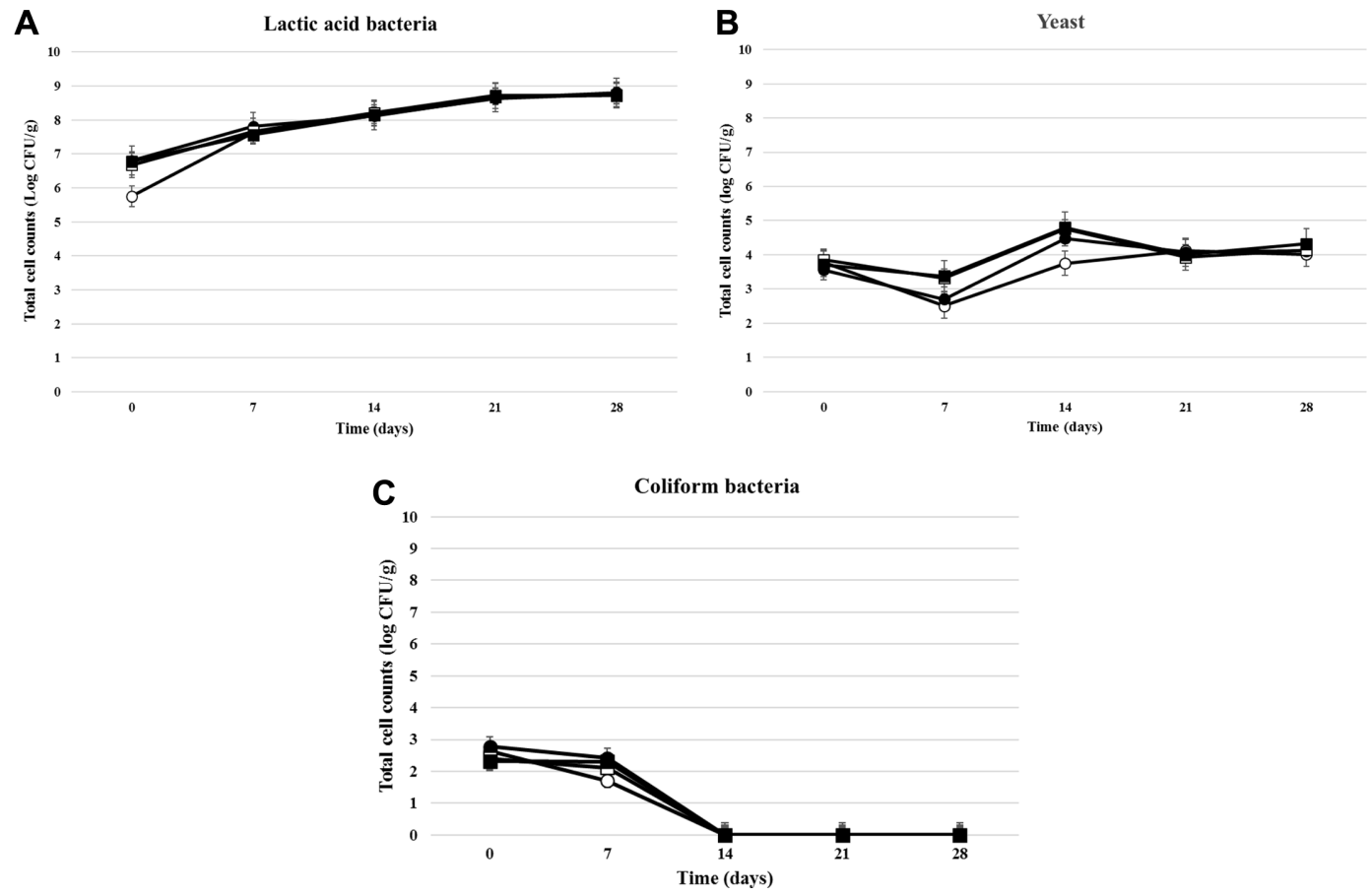

Fig. 3. Changes of microbial populations in kimchi samples during fermentation (four weeks). (A) Lactic acid bacteria, (B) Yeast, (C) Coliform bacteria: $\bigcirc$, Kimchi A (non-starter); - Kimchi B (LAB mix stater); $\square$, Kimchi C (Leu. mesenteroides PBio03); $\mathbf{\square}$, Kimchi D (Leu. mesenteroides PBio104). 
(Fig. 3). The initial LAB counts for kimchi C (PBio03) and kimchi D (PBio104) were $4.80 \times 10^{6} \mathrm{CFU} / \mathrm{g}$ and $6.00 \times$ $10^{6} \mathrm{CFU} / \mathrm{g}$, which were 10 -fold higher than LAB counts for kimchi $\mathrm{A}$. The highest LAB counts $\left(5.39 \times 10^{9} \mathrm{CFU} / \mathrm{g}\right.$ and $5.29 \times 10^{9} \mathrm{CFU} / \mathrm{g}$ ) were observed at 28 days. The changes in LAB counts from starter kimchi samples showed a similar tendency [2].

PCA agar plates were used to count the total viable bacteria in the kimchi samples, and the numbers were quite similar to the LAB counts on MRS agar plates (results not shown). The results indicate that LAB were the most abundant microorganisms associated with kimchi fermentation. Yeasts were detected from all kimchi samples. The initial yeast counts of kimchi $\mathrm{C}$ and $\mathrm{D}$ were $7.20 \times 10^{3} \mathrm{CFU} / \mathrm{g}$ and $7.20 \times 10^{3} \mathrm{CFU} / \mathrm{g}$, respectively. After 7 days, the numbers decreased to $2.10-2.30 \times 10^{3} \mathrm{CFU} / \mathrm{g}$, and the counts of yeast increased to $5.75-6.24 \times 10^{4} \mathrm{CFU} / \mathrm{g}$ at 14 days, after which the number gradually decreased to $1.38-2.08 \times 10^{4} \mathrm{CFU} / \mathrm{g}$ at 28 days. At 7 days, kimchi C and D samples showed higher yeast counts than other kimchi samples. Yeasts appear during the later stages of kimchi fermentation and are considered undesirable for kimchi fermentation because they generate off-flavors and deteriorate the texture of kimchi by secreting pectinases $[7,16]$.

The initial counts of coliform bacteria were $2.10-6.00 \times 10^{2} \mathrm{CFU} / \mathrm{g}$, which gradually decreased with a decrease in $\mathrm{pH}$ during kimchi sample fermentation.

LAB species were identified by culture-independent methods using MRS agar plates. Thirty colonies on MRS agar plates were randomly selected from each sample (Table 5). For kimchi A (non-starter) at 7 days, 17 colonies (56.7\%) had sequences identical to those of heterofermentative LAB, such as Leu. mesenteroides and Weissella koreensis. At 28 days, 8 colonies $(26.7 \%)$ of the same sample (kimchi A) were sequenced and identified to match with the sequence of Leu. mesenteroides. Among the 30 colonies isolated from kimchi B (LAB mix starter), 13 colonies were of Leu. mesenteroides (43.3\%), 7 colonies were of Leu. citreum (23.3\%), and 10 colonies were of $L b$. sakei (33.3\%) at 7 days. At 28 days, 13 colonies (43.3\%) of kimchi B had sequences identical to those of heterofermentative LAB. Among the 30 colonies isolated from kimchi C (PBio03), 19 colonies were of Leu.

Table 5. Microbial population of lactic acid bacteria during 28 days.

\begin{tabular}{|c|c|c|c|}
\hline Storage times & Samples & Species & Clone numbers out of $30(\%)$ \\
\hline \multirow[t]{4}{*}{1 week } & Kimchi A & $\begin{array}{l}\text { Leuconostoc mesenteroides } \\
\text { Weissella koreensis } \\
\text { Lactobacillus sakei } \\
\text { Lactobacillus plantarum }\end{array}$ & $\begin{array}{c}14 / 30(46.7) \\
3 / 30(10.0) \\
11 / 30(36.7) \\
2 / 30(6.6)\end{array}$ \\
\hline & Kimchi B & $\begin{array}{l}\text { Leuconostoc mesenteroides } \\
\text { Leuconostoc citreum } \\
\text { Lactobacillus sakei }\end{array}$ & $\begin{array}{l}13 / 30(43.3) \\
7 / 30(23.3) \\
10 / 30(33.3)\end{array}$ \\
\hline & Kimchi C & $\begin{array}{l}\text { Leuconostoc mesenteroides } \\
\text { Weissella koreensis } \\
\text { Lactobacillus sakei }\end{array}$ & $\begin{array}{c}26 / 30(86.7) \\
1 / 30(3.3) \\
3 / 30(10.0)\end{array}$ \\
\hline & Kimchi D & $\begin{array}{l}\text { Leuconostoc mesenteroides } \\
\text { Weissella koreensis } \\
\text { Lactobacillus sakei }\end{array}$ & $\begin{array}{c}24 / 30(80.0) \\
2 / 30(6.7) \\
4 / 30(13.3)\end{array}$ \\
\hline \multirow[t]{4}{*}{3 weeks } & Kimchi A & $\begin{array}{l}\text { Leuconostoc mesenteroides } \\
\text { Lactobacillus sakei } \\
\text { Lactobacillus plantarum }\end{array}$ & $\begin{array}{c}11 / 30(36.7) \\
17 / 30(56.7) \\
2 / 30(6.6)\end{array}$ \\
\hline & Kimchi B & $\begin{array}{l}\text { Leuconostoc mesenteroides } \\
\text { Leuconostoc citreum } \\
\text { Lactobacillus sakei } \\
\text { Lactobacillus plantarum }\end{array}$ & $\begin{array}{c}8 / 30(26.7) \\
5 / 30(16.7) \\
11 / 30(26.7) \\
6 / 30(20.0)\end{array}$ \\
\hline & Kimchi C & $\begin{array}{l}\text { Leuconostoc mesenteroides } \\
\text { Lactobacillus sakei } \\
\text { Uncultured bacterium }\end{array}$ & $\begin{array}{c}22 / 30(73.4) \\
7 / 30(23.3) \\
1 / 30(3.3)\end{array}$ \\
\hline & Kimchi D & $\begin{array}{l}\text { Leuconostoc mesenteroides } \\
\text { Lactobacillus sakei } \\
\text { Lactobacillus plantarum }\end{array}$ & $\begin{array}{l}21 / 30(70.0) \\
4 / 30(13.3) \\
5 / 30(16.7)\end{array}$ \\
\hline \multirow[t]{4}{*}{4 weeks } & Kimchi A & $\begin{array}{l}\text { Leuconostoc mesenteroides } \\
\text { Lactobacillus sakei } \\
\text { Lactobacillus plantarum } \\
\text { Lactobacillus brevis }\end{array}$ & $\begin{array}{c}8 / 30(26.7) \\
15 / 30(50.0) \\
4 / 30(13.3) \\
3 / 30(10.0)\end{array}$ \\
\hline & Kimchi B & $\begin{array}{l}\text { Leuconostoc mesenteroides } \\
\text { Leuconostoc citreum } \\
\text { Lactobacillus sakei } \\
\text { Lactobacillus plantarum }\end{array}$ & $\begin{array}{c}9 / 30(30.0) \\
4 / 30(13.3) \\
14 / 30(46.7) \\
3 / 30(10.0)\end{array}$ \\
\hline & Kimchi C & $\begin{array}{l}\text { Leuconostoc mesenteroides } \\
\text { Lactobacillus sakei } \\
\text { Lactobacillus plantarum } \\
\text { No reaction (PCR) }\end{array}$ & $\begin{array}{c}16 / 30(53.3) \\
11 / 30(26.7) \\
2 / 30(6.7) \\
1 / 30(3.3)\end{array}$ \\
\hline & Kimchi D & $\begin{array}{l}\text { Leuconostoc mesenteroides } \\
\text { Lactobacillus sakei } \\
\text { Lactobacillus plantarum }\end{array}$ & $\begin{array}{c}17 / 30(56.6) \\
11 / 30(36.7) \\
2 / 30(6.7)\end{array}$ \\
\hline
\end{tabular}


Table 6. Sensory evaluation results of the kimchi samples using kimchi starter.

\begin{tabular}{cccccc}
\hline Samples & Taste & Color & Flavor & Texture & Overall acceptability \\
\hline Kimchi A & $3.00 \pm 0.71$ & $4.20 \pm 0.84$ & $3.40 \pm 0.55$ & $3.20 \pm 0.84$ & $3.00 \pm 0.71$ \\
Kimchi B & $3.80 \pm 0.54$ & $4.40 \pm 0.55$ & $4.00 \pm 0.71$ & $3.40 \pm 0.55$ & $3.40 \pm 0.55$ \\
Kimchi C & $3.60 \pm 0.54$ & $4.20 \pm 0.45$ & $3.60 \pm 0.55$ & $3.20 \pm 0.84$ & $3.40 \pm 1.14$ \\
Kimchi D & $3.20 \pm 0.45$ & $4.40 \pm 0.55$ & $3.80 \pm 1.30$ & $3.40 \pm 1.51$ & $3.00 \pm 0.71$ \\
\hline
\end{tabular}

mesenteroides (63.3\%), 8 colonies were of $L b$. sakei (26.7\%), and 2 colonies were of $L b$. plantarum (6.7\%), and 1 colony (3.3\%) could not be sequenced at 28 days. Among the 30 colonies isolated from kimchi D (PBio104), 17 colonies were of Leu. mesenteroides (56.6\%), 11 colonies were of $L b$. sakei (36.7\%), and 2 colonies were of $L b$. plantarum (6.7\%) at 28 days. Regarding the total cell counts of $\mathrm{LAB}$ during fermentation carried out at $30^{\circ} \mathrm{C}$, the number of Leuconostoc spp. initially increased and was followed by a rapid decrease when the number of Lactobacillus species increased at $\mathrm{pH}$ 4.0-4.5. However, a delay was noted in the time periods associated with increase and decrease in the numbers of LAB (Leuconostoc spp. and Lactobacillus spp.) at $5^{\circ} \mathrm{C}$ [17]. Thus, Leu. mesenteroides is widely used as a kimchi starter because the strains are expected to exert favorable effects on kimchi [18].

Sensory evaluation was conducted with a small group of people (Table 6). Overall acceptability of kimchi B and $\mathrm{C}$ was better than that of kimchi A. There was no significant difference in the taste of kimchi B and C samples. Kimchi samples using starter received better scores for taste and overall acceptability. However, there was no difference in color, flavor or texture among the samples, thereby indicating that the addition of starter did not significantly affect any of these characteristics.

In the present study, we demonstrated the isolation and characterization of useful kimchi starter for commercial kimchi production. The kimchi using selected starter such as Leu mesenteroides PBio03 is of high quality due to high production of mannitol. The product also has extended shelf life and low gas/acid production. The starters were screened by several properties such as mannitol production and acid resistance, and kimchi fermentation tests were performed using selected LAB starter. These results show that Leu mesenteroides PBio03 and PBio104 are useful as starters for commercial kimchi fermentation.

\section{Conflict of Interest}

The authors have no financial conflicts of interest to declare.

\section{References}

1. CAC. 2001. Codex, standard for kimchi (CODEX STAN 223-2001), pp.1-3. Codex Alimentarius Commission, Rome, Italy.

2. Chang JY, Chang HC. 2010. Improvements in the quality and shelf life of kimchi by fermentation with induced bacteriocinproducing strain, Leuconostoc citreum GJ7 as a starter. J. Food Sci. 76: M103-M110.

3. Cho SK, Eom HJ, Moon JS, Lim SB, Kim YK, Lee KW, et al. 2014. An improved process of isomaltooligosaccharide production in kimchi involving the addition of a Leuconostoc starter and sugars. Int. J. Food Microbiol. 170: 61-64.

4. Jeong SH, Lee HJ, Jung JY, Lee SH, Seo HY, Park WS, et al. 2013. Effects of red pepper powder on microbial communities and metabolites during kimchi fermentation. Int. J. Food Microbiol. 160: 252-259

5. Lee CW, Ko CY, Ha DM. 1992. Microfloral changes of the lactic acid bacteria during kimchi fermentation and identification of isolates. Kor. J. Appl. Microbiol Biotechnol. 20: 102-109.

6. Lee JS, Heo GY, Lee JW, Oh YJ, Park JA, Park YH, et al. 2005. Analysis of kimchi microflora using denaturing gradient gel electrophoresis. Int. J. Food Microbiol. 102: 143-150.

7. Chang HW, Kim KH, Nam YD, Roh SW, Kim MS, Jeon CO. et al. 2008. Analysis of yeast and archaeal population dynamics in kimchi using denaturing gradient gel electrophoresis. Int. J. Food Microbiol. 126: 159-166.

8. Ahmadash LSF, Min SG, Han SK, Hong Y, Kim HY. 2015. Effect of low salt concentrations on microbial changes during kimchi fermentation monitored by PCR-DGGE and their sensory acceptance. J. Microbiol. Biotechnol. 25: 2049-2057.

9. Soetaert W, Buchholz K, Vandamme EJ. 1995. Production of D-mannitol and D-lactic acid by fermentation with Leuconostoc mesenteroides. Agro Food Ind. HiTech 6: 41-44.

10. Carvalheiro F, Moniz P, Duarte LC, Esteves MP, Grio FM. 2011. Mannitol Production by lactic acid bacteria grown in supplemented carsob syrup. J. Ind. Microbiol. Biotechnol. 38: 221-227

11. Otgonbayar GE, Eom HJ, Kim BS, Ko JH, Han NS. 2011. Mannitol production by Leuconostoc citreum KACC91348P isolated from kimchi. J. Microbiol Biotechnol. 21: 968-971.

12. Lee KW, Park JY, Jeong HR, Heo HJ, Han NS, Kim JH. 2012. Probiotic properties of Weissella strains isolated from human faeces. Anaerobe 18: 96-102.

13. Jung JY, Lee SH, Lee HJ, Seo HY, Park WS, Jeon CO. 2012. Effect of Leuconostoc mesenteroides starter cultures on microbial communities and metabolites during kimchi fermentation. Int. J. Food Microbiol. 153: 378-387.

14. Jeong JY, Kim OS, Sung JM. 2011. Quality and fermentation characteristics of kimchi made with different types of dried red pepper (Capsicum annum L.). J. Food. Sci. Nutr. 16: 74-82.

15. Jeong SH, Lee SH, Jung JY, Choi EJ, Jeon CO. 2013. Microbial succession and metabolite changes during long-term storage of kimchi. J. Food Sci. 78: M763-M769.

16. Lee ME, Jang JY, Lee JH, Park HW, Choi HJ, Kim TW. 2015. Starter culture for kimchi fermentation. J. Microbiol. Biotechnol. 25: 559568 .

17. Choi SY, Lee MK, Choi KS, Koo YJ, Park WS. 1998. Changes of fermentation characteristics and sensory evaluation of kimchi on different storage temperature. Kor. J. Food Sci. Technol. 30: 644-649.

18. Jin HS, Kim JB, Yun YJ, Lee KJ. 2008. Selection of kimchi starters based on the microbial composition of kimchi and their effects. J. Kor. Soc. Food Sci. Nutr. 37: 671-675. 